\title{
Diets with Beef Tallow Prevent Acute Acetaminophen Hepatotoxicity Compared to Diets with Soybean Oil in a Rat Model
}

\author{
Jinah Hwang, ${ }^{* a}$ Hyun-Jeong Kwak, ${ }^{b}$ Joong-Yeon Lim, ${ }^{c}$ and Eugene Shim ${ }^{d}$ \\ ${ }^{a}$ Department of Foods and Nutrition, College of Natural Sciences, Myongji University, San 38-2, Nam-Dong, Cheoin-Gu, YongIn, \\ Gyeonggi-Do 449-728, Republic of Korea, ${ }^{b}$ Division of Cardiovascular Diseases and ${ }^{c}$ Division of Intractable Diseases, Department \\ of Biomedical Sciences, National Institutes of Health, 194 Tongil-Lo, Eunpyung-Gu, Seoul 122-701, Republic of Korea and d National \\ Hypertension Center, Yonsei University Health System, 134 Sinchon-Dong, Seodaemun-Gu, Seoul 120-752, Republic of Korea
}

(Received December 10, 2009; Accepted April 18, 2010)

\begin{abstract}
Dietary polyunsaturated fatty acids (PUFA) increase liver injury in response to ethanol feeding. We tested the hypothesis that diets rich in linoleic acid (18:2 n-6) would also affect acute liver injury after acetaminophen injection. To determine whether the types and quantity of dietary fats were important, we examined the effects of feeding diets with either 7 or $15 \mathrm{~g}$ per $100 \mathrm{~g}$ soybean oil or beef tallow. After the feeding period, animals were unfed and injected either with $600 \mathrm{mg} / \mathrm{kg}$ body weight acetaminophen suspended in gum arabic-based vehicle, or with vehicle alone. Samples of plasma and liver were taken for analyses of liver-specific enzymes, [glutamatepyruvate transaminase (GPT) and glutamate-oxaloacetate transaminase (GOT)] and hepatic glutathione (GSH) and thiobarbituric reactive substances (TBARS) levels, respectively. Treatment with acetaminophen significantly elevated levels of plasma GOT and GPT as well as hepatic TBARS but reduced hepatic GSH levels in groups fed diets with soybean oil compared to beef tallow. The feeding regimens changed the ratio of $18: 2 \mathrm{n}-6$ to oleic acid (18:1 $\mathrm{n}-9)$ in liver membrane phospholipid approximately 4- to 6-fold, and produced modest changes in arachidonic acid (20:4 n-6). We conclude that acetaminophen-induced hepatotoxicity can be protected with more saturated fatty acids (SFA)-rich diet but can be exacerbated with PUFA-rich diet by modulating the tissue fatty acid composition.
\end{abstract}

Key words__ dietary fatty acids, membrane phospholipid composition, hepatotoxicity

\section{INTRODUCTION}

Dietary unsaturated fats such as corn oil, soybean oil, and fish oil influence health and several disease processes. The average diet in United States contains $33 \%$ of total calories as fat. ${ }^{1)}$ In addition to a lowering of saturated fat intake, an increase in unsaturated fats, such as linoleic acid (18:2 n-6), generally has been recommended due to the ability of polyunsaturated fatty acids (PUFA) to reduce serum cholesterol, a risk factor for heart disease. However, PUFA are the most peroxidizable fatty acids and may contribute to diseases related to inflammation in which eicosanoids are released from tissues

\footnotetext{
*To whom correspondence should be addressed: Department of Foods and Nutrition, College of Natural Sciences, Myongji University, San 38-2, Nam-Dong, Cheoin-Gu, YongIn, Gyeonggi-Do 449-728, Republic of Korea. Tel.: +82-31-3306205; Fax: +82-31-330-6200; E-mail: jhwang@mju.ac.kr
}

and contribute to pathologies.

It has been suggested that the type of dietary fats can influence the extent of the formation of lipid radicals and hence lipid peroxidation products in response to oxidative injury because any change in dietary fats is reflected in membrane composition. ${ }^{2,3)}$ For example, PUFA are more prone to oxidation than saturated fatty acids (SFA) and monounsaturated fatty acids (MUFA) ${ }^{2,4,5)}$ and increase susceptibility to oxidative injury by affecting antioxidant defense systems. ${ }^{6)}$ Under some experimental conditions, PUFA produce adverse effects that presumably result from their susceptibility to peroxidation. For instance, PUFA from corn oil and fish oil augment oxidative stress, hepatic inflammation and pathology, whereas dietary SFA in beef and pork are protective against alcohol-induced liver disease in humans and animals. $2,4,7-10$ )

Lands and colleagues ${ }^{11,12)}$ have built a quantita- 
tive saturation model of the response of membrane phospholipids to dietary fat composition, which was presented as a series of mathematical equations. The model implicates that membranes are saturated with individual phospholipids when specific n-3 and n-6 precursors are present at about $0.5-$ $1.0 \%$ of total calories, with half-maximal responses at about $0.1 \%$. However, the relative proportion of specific highly unsaturated fatty acids (HUFA) depends on the relative concentration of the precursors in the diet. Therefore, it is not feasible to decrease the abundance of arachidonic acid very significantly by changing the amount of oil consumed, even for low-fat rodent diets. But changing the relative amount of competing n-3 and n-6 PUFA precursors is highly effective in altering the proportions of n-3 and n-6 HUFA in membranes. Therefore, ratios of SFA:MUFA:PUFA are more important than absolute quantities of dietary fats. The American Institute of Nutrition 93 (AIN 93) rodent diet contains 7\% soybean oil by weight, which has $14.4 \mathrm{~g}$ SFA, 23.3 g MUFA, and 57.9 g PUFA per 100 g. ${ }^{13)}$ Thus, the AIN 93 rodent diet is a high linoleic acid diet that is not in balance with respect to these constituents. The rodent diet contains $16.7 \%$ of its total energy as fat, and would be low by human standards.

Hepatotoxicity caused by acetaminophen is due to the formation of a toxic metabolite by the cytochrome P-450 system, which is known to be susceptible to dietary manipulation. Some evidence ${ }^{8,14-16)}$ have shown that increased cytochrome P-450 levels, cytochrome 2E1, and microsomal mixed function oxidase (MFO) activity in animals fed PUFA compared to SFA might account, in part, for the liver injury. Specifically linoleic acid as well as the HUFA found in the fish oils [eicosapentaenoic acid (EPA) and docosahexaenoic acid (DHA)] have been shown to be important in this respect. ${ }^{17)}$ Also, acetaminophen administration as well as high PUFA intake increase the activity of hepatic enzymes such as glutamate-pyruvate transaminase (GPT) and glutamate-oxaloacetate transaminase (GOT) and cause cell damage that increases the excretion of these enzymes into blood. ${ }^{18)}$

We have chosen a rat model of hepatotoxicity to test the hypothesis that diets with SFA (beef tallow) prevent liver injury after acetaminophen challenge when compared to diets with PUFA (soybean oil) by changing the fatty acid composition of membrane phospholipids. We also tested whether protective effects depend on the quantity of dietary fats.

\section{MATERIALS AND METHODS}

Animals and Diets — Fifty-four male SpragueDawley rats (Charles River, Morrisville, NC, U.S.A.) weighing 150-190 g were housed individually in hanging wire-mesh cages with feeding cups. The room temperature $\left(21 \pm 1^{\circ} \mathrm{C}\right)$, lighting (on at 06:00, off at 18:00), and humidity (40$50 \%$ ) were controlled. Rats had free access to restricted experimental diets ( $15 \mathrm{~g}$ per day) and tap water. The rats were randomly assigned to five groups. The semipurified control diet was fed for one week to acclimate the animals to feed cups and individual caging and all rats were fed the same AIN 93G diet ${ }^{13)}$ containing 7\% (wt/wt) soybean oil for 2 weeks. Rats in group $0(n=6)$ were unfed overnight and killed to obtain an initial fatty acid profile. Rats in group 1 were continued on the same AIN 93G diet, and rats in groups 2,3 , and 4 were switched to diets containing either $15 \%$ soybean oil, $7 \%$ beef tallow, or $15 \%$ beef tallow for 4 more weeks, respectively. The low fat diets were made isocaloric by increasing dyetrose (Dyets, Bethlehem, PA, U.S.A.). All diets also contained: Sucrose $100 \mathrm{~g} / \mathrm{kg}$, Celufil (SolkaFloc, North Tonawanda, NY, U.S.A.), $50 \mathrm{~g} / \mathrm{kg}$; Mineral mix (AIN-93G-MX), $35 \mathrm{~g} / \mathrm{kg}$; Vitamin mix (AIN-93-VX), $10 \mathrm{~g} / \mathrm{kg}$; Choline bitartrate, $2.5 \mathrm{~g} / \mathrm{kg}$; L-cysteine, $3 \mathrm{~g} / \mathrm{kg}$; and Tert-butylhydroquinone, $0.014 \mathrm{~g} / \mathrm{kg}$. Each group was fed the indicated diets for six weeks to enable membrane phospholipids to equilibrate with the diet pattern. The fatty acid composition of the soybean oil, and beef tallow is shown in Table 1.

At the end of the 6 weeks feeding period, each

Table 1. Fatty Acid Composition of the Soybean Oil and Beef Tallow

\begin{tabular}{|c|c|c|}
\hline \multirow[t]{2}{*}{ Fatty acid } & Soybean oil & Beef tallow \\
\hline & \multicolumn{2}{|c|}{$(\mu$ mole $\%)$} \\
\hline C14:0 & - & 2.3 \\
\hline C16:0 & 7.3 & 29.8 \\
\hline C18:0 & 3.7 & 23.3 \\
\hline C18:1 n-9 & 23.5 & 34.2 \\
\hline C18:2 n-6 & 62.1 & 2.7 \\
\hline C18:3 n-3 & 3.7 & - \\
\hline$\Sigma$ SFA & 11.0 & 55.4 \\
\hline$\Sigma$ MUFA & 23.5 & 34.2 \\
\hline$\Sigma$ PUFA & 65.8 & 2.7 \\
\hline
\end{tabular}


group ( $n=12)$ was randomly subdivided into case $(n=6)$ and control $(n=6)$ groups. Each case group was unfed overnight prior to acetaminophen challenge and for $2 \mathrm{hr}$ afterwards, and was given food again before killing. ${ }^{19)}$ Acetaminophen was given intraperitoneally in a vehicle of gum arabic ( $2 \%$ in saline) at a dose of $600 \mathrm{mg} / \mathrm{kg}$ body weight. After $7 \mathrm{hr}$, animals were anesthetized with ketamine : acepromezine : xylazine $(3: 2: 1)$ at a dose of $0.1 \mathrm{ml} / 100 \mathrm{~g}$ body weight and blood samples were collected by cardiac puncture in tubes containing $3.2 \%$ sodium citrate. Tubes were centrifuged at $2000 \mathrm{rpm}$ for $20 \mathrm{~min}$ to obtain plasma for liver function tests. The animals then were perfused transcardially with $0.9 \% \mathrm{NaCl}$ and livers were snapfrozen. All frozen samples were stored at $-80^{\circ} \mathrm{C}$ for later experiments.

\section{Measurement of Plasma GPT and GOT -} GPT and GOT were measured with the Sigma transaminase [alanine aminotransferase (ALT)/GPT and aspartate aminotransferase (AST)/GOT] Diagnostic kit (Shigma-Aldrich, St. Luis, MO, U.S.A.). A standard curve was prepared using the Calibration Standard Solution with six levels of pyruvic acid. In brief, $0.2 \mathrm{ml}$ plasma was added to $1.0 \mathrm{ml}$ Sigma Prepared Substrate for GOT or $1.0 \mathrm{ml}$ Alaninealpha-ketoglutarate $(\alpha$-KG) Substrate for GPT in a $37^{\circ} \mathrm{C}$ water bath for $1 \mathrm{hr}$ and for $30 \mathrm{~min}$, respectively. Then $1.0 \mathrm{ml}$ Sigma Color Reagent was added and incubated at room temperature $\left(18-26^{\circ} \mathrm{C}\right)$ for $20 \mathrm{~min}$, followed by adding $10.0 \mathrm{ml}$ of $0.40 \mathrm{~N} \mathrm{NaOH}$ with vigorous mixing. Absorbance at $505 \mathrm{~nm}$ was recorded and the enzyme activities were determined in Sigma-Frankel (SF) Units/ml from the calibration curves.

\section{Measurement of Hepatic Glutathione} (GSH) — Reduced GSH was measured by the method of Sedlak and Lindsay. ${ }^{20)}$ A standard curve was prepared using reduced GSH in $0.02 \mathrm{M}$ EDTA. The curve was linear between 3.0 and $100.0 \mathrm{nmols}$ GSH and data were expressed as $\mu$ mole GSH per $\mathrm{g}$ tissue. Briefly, $600 \mu \mathrm{l}$ aliquots of homogenate were treated with $60 \mu \mathrm{l}$ of $55 \%$ trichloroacetic acid, shaken well and allowed to stand on ice for $10 \mathrm{~min}$, followed by centrifugation at $4000 \mathrm{~g}$ for $12 \mathrm{~min}$. Four hundred $\mu \mathrm{l}$ of the supernatant was mixed with $1.0 \mathrm{ml}$ of $1.2 \mathrm{M}$ Tris in $0.06 \mathrm{M}$ EDTA (pH 8.9) and $100 \mu \mathrm{l}$ of Ellman's reagent [5,5'-dithiobis-2-nitrobenzoic acid (DTNB)]. The samples were allowed to develop at room temperature for $15 \mathrm{~min}$ and absorbance at $412 \mathrm{~nm}$ was recorded.
Lipid Peroxidation - Lipid peroxidation was evaluated by thiobarbituric reactive substances (TBARS) according to the method of Ciuffi et al. ${ }^{21)}$ In brief, frozen tissue samples were homogenized in ice-cold phosphate buffer $(0.05 \mathrm{M}, \mathrm{pH} 7.4)$ and immediately treated with thiobarbituric acid and placed in a boiling water bath for $12 \mathrm{~min}$. This procedure was followed by butanol extraction and subsequent reading of the supernatants at $532 \mathrm{~nm}$. The equivalent malondialdehyde (MDA) concentration was calculated on the basis of the molar extinction coefficient of the MDA-thiobarbituric acid complex $\left(1.56 \times 10^{5} \mathrm{M}^{-1} \cdot \mathrm{cm}^{-1}\right)$. A standard curve was prepared using 1,1,3,3-tetraethoxypropane. The curve was linear between 0.01 and 1.5 nmoles of MDA. Data are expressed as nmole MDA per mg protein.

Preparation of Liver Microsomes — The liver was suspended in $25 \%$ homogenizing buffer in icecold $1.15 \% \mathrm{KCl} / 50 \mathrm{mM}$ Tris-HCl/1 mM EDTA (pH 7.4), homogenized and centrifuged at $10000 \mathrm{~g}$ at $4^{\circ} \mathrm{C}$ for $20 \mathrm{~min}$. The resulting supernatant was centrifuged at $105000 \mathrm{~g}$ for $1 \mathrm{hr}$ at $4^{\circ} \mathrm{C}$ and the microsomal pellet was suspended in $0.1 \mathrm{M}$ potassium phosphate buffer (pH 7.4).

Fatty Acid Analysis — Extraction of fatty acids from phospholipids of liver microsomes was performed using the method of Folch et al. ${ }^{22)} \mathrm{Ex}-$ tracted fatty acids were applied to silica gel $\mathrm{G}$ Thin layer chromatography (TLC) plates. After the application, solvent was allowed to dry and the plate was fully developed to $18 \mathrm{~cm}$ in acetone/acetic acid/water (100:2:1, by vol.). The lipid classes were visualized by spraying the plates with rhodamine $6 \mathrm{G}(0.02 \%$ in $95 \%$ ethanol) and exposing the plates to ultraviolet light. All of the silica in phospholipid band was scraped into 10-ml screwcapped tubes (Teflon-lined caps) and refluxed with $3 \mathrm{ml}$ of $6 \% \mathrm{HCl}$ in methanol and $40 \mu \mathrm{l}$ of internal standard (heptadecanoic acid, C 17:0, Nu Chek, Elysian, MN, U.S.A.) and transmethylated at $75^{\circ} \mathrm{C}$ for $2 \mathrm{hr}$. The tubes were cooled on ice and $2 \mathrm{ml}$ of hexane and $1 \mathrm{ml}$ of $0.1 \mathrm{M} \mathrm{KCl}$ were added, and the tubes were vortexed for $1 \mathrm{~min}$ and centrifuged at $1000 \mathrm{rpm}$ for $10 \mathrm{~min}$. The hexane extract (upper phase) was passed through a sodium sulfate column and was concentrated under a stream of nitrogen for gas chromatography (GC) analysis.

Fatty acid analysis was performed with a Hewlett-Packard 5890 GC using a flexible fused capillary column $[30 \mathrm{~m} \times 0.25 \mathrm{~mm}$ internal diameter (I.D.): thickness $0.25 \mu \mathrm{m}, \mathrm{J} \& \mathrm{~W}$ Scientific, Folsom, CA, U.S.A.]. The column temperature was 

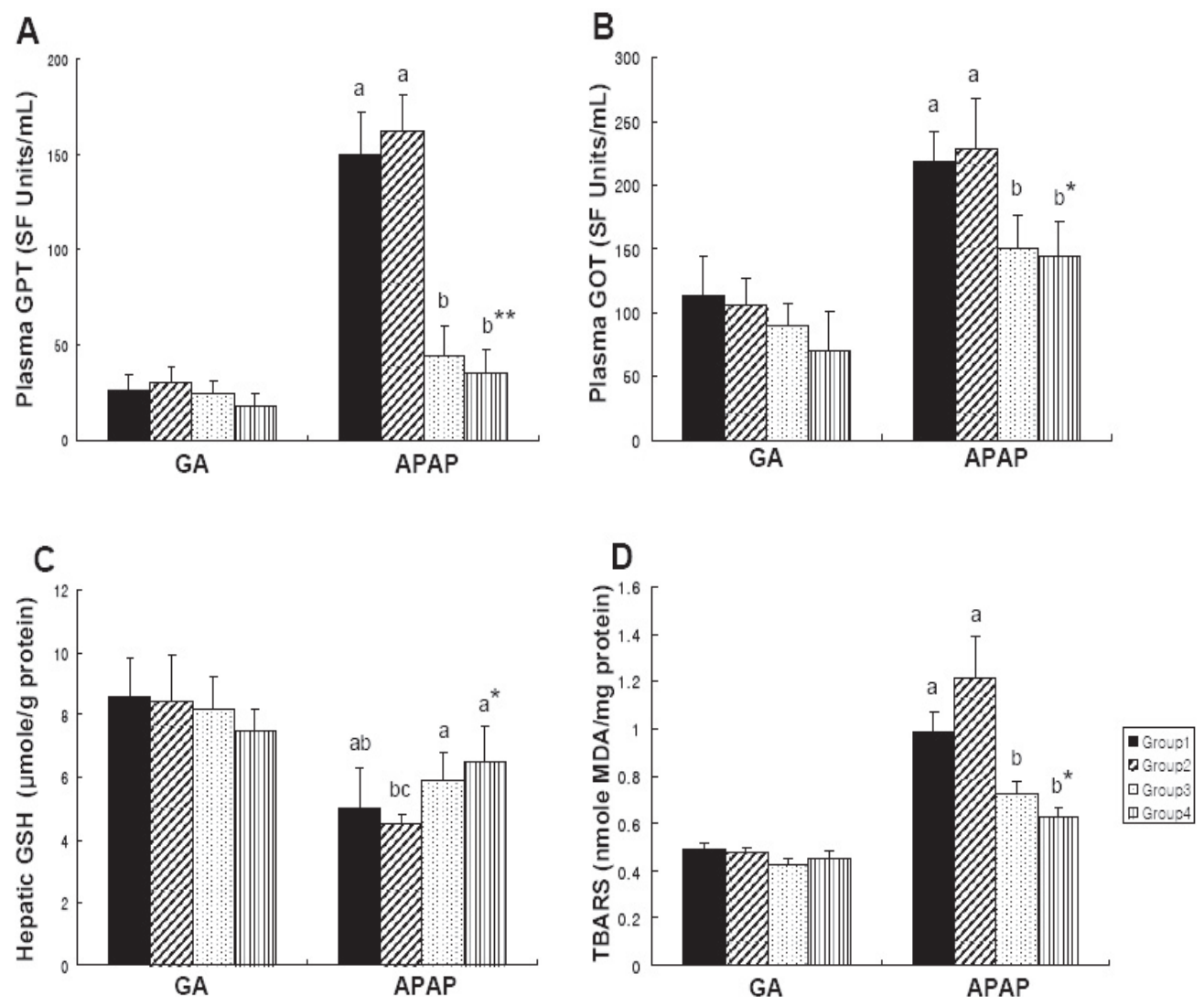

Fig. 1. The Effect of Acetaminophen on GPT (A), GOT (B), Hepatic GSH (C) and TBARS (D) Levels

Abbreviations: Group 1, 7\% soybean oil for 6 weeks; Group 2, 7\% soybean oil for 2 weeks $+15 \%$ soybean oil for 4 weeks; Group 3, 7\% soybean oil for 2 weeks $+7 \%$ beef tallow for weeks; Group 4, 7\% soybean oil for 2 weeks $+15 \%$ beef tallow for 4 weeks; GA, gum arabic vehicle injected to control group; APAP, acetaminophen injected to case group. Each bar represents the mean \pm S.E. $(n=6)$. Different letters $(a, b \& c)$ indicate significant difference among APAP groups $\left({ }^{*} p<0.05,{ }^{* *} p<0.01\right)$.

programmed to begin at $205^{\circ} \mathrm{C}$ for $20 \mathrm{~min}$ and then increase at a rate of $3^{\circ} \mathrm{C} / \mathrm{min}$ to a final temperature of $220^{\circ} \mathrm{C}$, which held for $3 \mathrm{~min}$. The injection port temperature was $250^{\circ} \mathrm{C}$ and the detector was $260^{\circ} \mathrm{C}$. Fatty acid values were presented as $\mu$ mole $\%$ which represents the area under the chromatograph identified as a particular fatty acid based on its retention time when compared to the internal standard.

Statistical Analysis — All data were presented as mean \pm S.D. The data were analyzed with nonparametric method due to small sample sizes using Statistical Analysis System (SAS) computerbased statistics programs (SAS Institute, Cary, NC, U.S.A.). Kruskal-Wallis tests and the Wilcoxon rank sum tests were performed for one-way analysis of variance and statistical differences between two groups, respectively. Correlations between variables were done using Pearson's correlation coefficient. Differences with $p<0.05$ were considered statistically significant.

\section{RESULTS}

\section{Body Weight and Liver Weight per 100 g Body Weight}

There were no significant differences in the initial and final body weights between different dietary groups, which increased approximately from 226 to $330 \mathrm{~g}$ after the 6 week feeding period (data not shown). There were no significant differences in liver weight per $100 \mathrm{~g}$ body weight, ranged from 2.71 to $3.06 \mathrm{~g}$ among the groups (data not shown).

\section{Plasma GPT and GOT Concentrations}

Plasma GOT and GPT levels increased significantly after acute intoxication with acetaminophen in animals fed soybean oil (Fig. 1A and 1B). In contrast, animals fed beef tallow showed no significant differences after acetaminophen challenge compared to gum arabic-injected control animals (Fig. 1A and 1B). Moreover, diets with beef tallow showed significantly reduced levels of GPT and 
Table 2. Fatty Acid Composition of Phospholipids in Liver Microsomes

\begin{tabular}{|c|c|c|c|c|c|c|}
\hline \multirow[t]{2}{*}{ Fatty acid } & \multirow{2}{*}{$\begin{array}{c}2 \text { week } \\
\text { Group } 0\end{array}$} & \multicolumn{4}{|c|}{6 weeks } & \multirow[b]{2}{*}{$\overline{\mathrm{P} \text { value }}{ }^{1)}$} \\
\hline & & Group 1 & $\begin{array}{c}\text { Group } 2 \\
(\mu \text { mole } \%)\end{array}$ & Group 3 & Group 4 & \\
\hline C14:0 & $0.51 \pm 0.62$ & $0.52 \pm 0.93$ & $1.44 \pm 1.62$ & $2.37 \pm 1.77$ & $1.15 \pm 0.82$ & 0.153 \\
\hline C16:0 & $22.6 \pm 3.08^{b}$ & $26.2 \pm 3.47^{a}$ & $21.1 \pm 0.79^{b}$ & $22.7 \pm 2.60^{b}$ & $21.6 \pm 1.87^{b}$ & 0.029 \\
\hline C16:1 & $0.54 \pm 0.28^{b}$ & $0.86 \pm 2.49^{b}$ & $0.59 \pm 0.45^{b}$ & $1.34 \pm 1.83^{a b * *}$ & $1.50 \pm 0.69^{a b * 2)}$ & 0.043 \\
\hline C18:0 & $20.7 \pm 3.59^{b}$ & $20.3 \pm 1.93^{b}$ & $23.4 \pm 0.52^{a *}$ & $21.0 \pm 2.97^{a b}$ & $23.8 \pm 1.78^{a}$ & 0.018 \\
\hline C18:1 & $2.72 \pm 0.48^{b}$ & $2.15 \pm 0.67^{b}$ & $1.65 \pm 0.30^{b *}$ & $5.80 \pm 1.39^{a *}$ & $6.71 \pm 0.73^{a * *}$ & 0.0001 \\
\hline C18:2 & $13.2 \pm 0.82^{a}$ & $13.3 \pm 1.80^{a}$ & $14.6 \pm 0.93^{a}$ & $7.11 \pm 1.28^{b * * *}$ & $7.76 \pm 1.19^{b * *}$ & 0.0001 \\
\hline $\mathrm{C} 18: 2 / \mathrm{C} 18: 1^{3)}$ & $5.00 \pm 1.22^{b}$ & $5.97 \pm 1.31^{b}$ & $8.43 \pm 1.37^{a * *}$ & $1.74 \pm 1.14^{c * *}$ & $1.37 \pm 0.16^{c * *}$ & 0.0001 \\
\hline $\mathrm{C} 18: 3$ & $0.12 \pm 0.13$ & $0.13 \pm 0.17$ & $0.18 \pm 0.15$ & $0.21 \pm 0.23$ & $0.19 \pm 0.19$ & 0.179 \\
\hline C20:4 & $28.4 \pm 5.49^{a}$ & $28.7 \pm 4.41^{a}$ & $29.4 \pm 2.93^{a}$ & $25.5 \pm 2.78^{b}$ & $26.6 \pm 1.32^{a b}$ & 0.024 \\
\hline C20:5 n-3 & $0.96 \pm 0.69$ & $1.07 \pm 0.98$ & $1.27 \pm 1.02$ & $1.63 \pm 1.78$ & $1.53 \pm 0.99$ & 0.169 \\
\hline$C 22: 6 n-3$ & $2.21 \pm 1.96$ & $2.16 \pm 1.63$ & $2.35 \pm 1.36$ & $2.39 \pm 2.35$ & $2.64 \pm 1.89$ & 0.175 \\
\hline
\end{tabular}

Values are means \pm S.D. 1) $p$ value by Kruskal-Wallis test. Different superscripts for $(a, b, \& c)$ each fatty acid mean significantly different levels among groups. 2) ${ }^{*} p<0.05,{ }^{* *} p<0.01$, and ${ }^{* * *} p<0.001$ compared with group 0 (2 weeks) and each group after 6 weeks by Wilcoxon Rank Sum test. 3) The ratios of linoleic acid to oleic acid.

GOT compared to diets with soybean oil. Regardless of the amount of dietary fats, diet with beef tallow protected against liver injury as judged by the increase in plasma activity of liver-specific marker enzymes after acetaminophen-induced intoxication.

\section{Hepatic GSH and TBARS Concentrations}

Within the same diet groups, liver GSH concentrations of acetaminophen-injected groups were significantly lower in animals fed soybean oil (Fig. 1C). Lipid peroxidation measured by TBARS was significantly reduced in animals fed beef tallow compared to soybean oil, irrespective of amounts of dietary fats (Fig. 1D). Pearson's correlation analysis showed that hepatic GSH levels had negative correlation with lipid peroxidation measured by TBARS in the same animal groups $(r=-0.7093, p=$ 0.0007) (data not shown).

\section{Fatty Acid Composition of Liver Membranes}

Because the type and amount of dietary fat are reflected in tissue fatty acid profiles, fatty acid compositions were determined for phospholipids in liver microsomes (Table 2). Soybean oil-fed rats showed significantly much higher 18:2 n-6 and much lower 18:1 n-9 than beef tallow-fed animals. Beef tallow fed animals showed more than 2-fold increase in 18:1 n-9 and a 50\% decrease in 18:2 n- 6 after 4 weeks of feeding. Thus, the feeding regimens changed the ratio of $18: 2$ n- 6 to $18: 1$ n-9 in liver phospholipid approximately 4- to 6-fold and produced modest changes in arachidonic acid (20:4 n6). Change in amounts of soybean oil from $7 \%$ to $15 \%$ showed significant higher $16: 0$ and lower 18:0 and 18:2/18:1 in 7\% than $15 \%$ soybean oil-fed group. However, no significant differences were observed in tissue the fatty acid compositions between $7 \%$ and $15 \%$ diets with beef tallow.

\section{DISCUSSION}

This present study hypothesized that diets with high SFA (beef tallow) prevent liver injury after acetaminophen challenge when compared to diets with high PUFA (soybean oil) by changing the fatty acid composition of membrane phospholipids. We also tested whether these effects are dependant on the quantity of dietary fats. The results indicate that acetaminophen hepatotoxicity was significantly lower in rats fed diets containing high SFA, that is, low PUFA compared to rats fed diets containing high PUFA. This protective effect was manifested in the concentrations of liver-specific markers. Animals fed PUFA had significantly elevated plasma GPT and GOT levels as well as TBARS levels and decreased GSH levels after acetaminophen challenge, which was not dependent on the amounts of dietary fats. Although the mechanism of these effects is unclear, these effects may be related to the observed changes in membrane fatty acid composition. The feeding of soybean oil changed the ratio of linoleic to oleic acids in liver phospholipid approximately 4- to 6-fold higher than beef tallow diet.

Although it is sometimes controversial regarding the relationship between dietary fats and lipid 
profiles such as total cholesterol, triacylglyceride (TG), low-density lipoprotein (LDL), and highdensity lipoprotein (HDL), ${ }^{23-25)}$ PUFA-rich diets generally provide better lipid profiles than SFArich diets and have beneficial effects on risk factors for atherosclerosis and cardiovascular disease. ${ }^{26,27)}$ However, in our study, since we focused on SFA protection and PUFA deterioration in drug-induced toxicity model by dietary fats we avoided to repeat the measurement of general lipid profiles.

Fatty acid composition of cellular membranes and, in particular, the MUFA and PUFA content are highly dependent on the fat composition of the diet by de novo synthesis or by elongation from dietary precursors. ${ }^{15,28)}$ This was particularly significant with 18:1 n-9 and 18:2 n-6 in our data. In liver membranes from rats fed soybean oil, levels of 18:2 were 2- to 3-fold those found in liver membrane from beef tallow fed rats and 18:1 n-9 showed opposite trends. These differences in membrane composition may cause alterations in enzyme activity and subsequent differences in drug metabolism and toxicity by altering membrane conformation and fluidity. ${ }^{29,30)}$ Moussa et al. ${ }^{31)}$ suggested that lymphocyte phospholipid preferentially stimulated the synthesis of MUFA, especially 18:1 n-9, by increasing $\Delta 9$-desaturase activity rather than SFA uptake in SFA-rich coconut-oil diets. Some evidence have supported suppressive synthesis of $18: 1 \mathrm{n}-9$ by $\mathrm{n}-$ 6 PUFA rich $\operatorname{diet}^{28)}$ and inhibitory activity of $\Delta 9$ desaturase by an excess of linolenyl-CoA, which is metabolized from 18:2 n-6. ${ }^{32)}$ Saito et al. ${ }^{33)}$ reported that 14 days feeding of $15 \%$ and $25 \%$ lard or sardine oil did not produce any significant differences in liver microsomal fatty acid composition.

The changes in microsomal fatty acid composition in rats fed SFA diet, which is low in 18:2 n6 may be related to the hepatoprotective effect of this diet. French et al. ${ }^{7)}$ supported this hypothesis by showing that a diet low in 18:2 n-6 prevented the fatty acid changes (e.g., reduction in 20:4 n-6) seen with ethanol feeding and protected against mitochondrial fragility caused by ethanol ingestion. ${ }^{2)}$ Several workers have suggested, in part, possible mechanisms that dietary 18:2 n-6 level was a major factor in influencing oxidative stress. More intake of corn oil ( 5-70\% of total energy intake) produced more 18:2 n-6, which easily oxidizes and generates cytotoxic products, such as linoleic acid hydroperoxides, ${ }^{34)}$ or 4-hydroxy-2-(E)-nonenal, ${ }^{35)}$ elevated oleic acid may exert antioxidant effects on lipid peroxidation, acting as a competitive inhibitor of oxida- tion of PUFA. ${ }^{36,37)}$ Although oleic acid can undergo oxidation with one double bond, they can not amplify propagative reactions due to their lack of multiple double bonds and thus their rate of oxidation is much less than that of PUFA. PUFA are excellent targets for lipid peroxidation because the formation of free radical is propagated to amplify the reaction. Recently mounting evidences have shown that diets with high 18:1 n-9 and low 18:2 n-6 may be protective effects against diseases. ${ }^{15,37-39)}$

Reduction of 20:4 n-6 may decrease the formation of eicosanoids and promote less free radical generation. ${ }^{79)}$ Nanji et al. ${ }^{8,9)}$ also suggested that this hepatoprotective effect might be caused by diminishing the availability of substrate for lipid peroxidation in the liver with substitution of PUFA with SFA. Therefore, decreased levels of this peroxidizable fatty acid may account, in part, for the absence of liver injury. Moreover, 20:4 n-6 might contribute to increased oxidation in animals fed corn oil rich in 18:2 $n-6$. $^{6}$ They also suggested that corn oilfed animals had low scavenging capacity to quench free radicals and the low resistance to peroxidation when compared to animals fed more SFA diets. Nanji et al. ${ }^{10,40)}$ showed that both prostaglandin $\mathrm{E}_{2}$ and 6-keto-prostaglandin $\mathrm{F} 1 \alpha$ were reduced in liver nonparenchymal cell, which was related to pathological liver injury in rats fed corn oil and ethanol. Acetaminophen-induced liver injury in vivo was significantly reduced by prostacyclin which is considered to be cytoptotective. ${ }^{10,40,41)}$

We examined our hypothesis that PUFA may result in increased levels of lipid peroxidation. In view of significantly higher values of biochemical markers of liver damage (e.g. increased plasma levels of GPT, GOT and TBARS) as well as decreased GSH levels, it is supported that PUFA can induce liver injury. Models of drug-induced liver toxicity involve at least four different components, including increased levels of cytochrome P-450; provision of substrate that generate free radicals; targets susceptible to free radical damage; and deletion of cellular antioxidants.

Liver toxicity caused by acetaminophen is due to the formation of a toxic metabolite by the cytochrome P-450 system, a system known to be susceptible to dietary manipulation. Some evidence $^{14,17,33,42)}$ have shown that increased cytochrome P-450 levels, especially $2 \mathrm{E} 1$, and microsomal MFO activity in animals fed PUFA compared to SFA might account, in part, for the liver injury. 
This isoenzyme induction by PUFA is involved in the activation of $\mathrm{N}$-acetyl- $p$-benzoquinoneimine, an acetaminophen metabolite, and thus enhances acetaminophen toxicity. In another study, we immunoblotted protein levels of cytochrome 2E1 after $15 \%(\mathrm{wt} / \mathrm{wt}$ ) corn oil, olive oil, and beef tallow for 6 weeks. Treatment with acute acetaminophen significantly induced cytochrome 2E1 levels in corn oilfed rats (3-fold increase compared to vehicle control), but not in olive oil- and beef tallow-fed rats (unpublished data, Hwang et al.). Yoo et al. ${ }^{43)}$ reported that $20 \%$ corn oil or linoleic acid equivalent increased in the concentration of cytochrome P-450 2E1 by 2- to 3-fold. Specifically, 18:2 n-6 as well as the highly unsaturated, long chain fatty acids found in the fish oils (EPA and DHA) have all been shown to be important in this respect. ${ }^{17,33)}$

Dietary fat may alter the activity of cytochrome P-450 by altering its intramembrane positioning, which may increase its reactivity with substrates. ${ }^{15)}$ The fatty acid composition of the cell membrane is highly susceptible to dietary manipulation, and changes in fatty acid occurred in endoplasmic reticulum after only 1-2 days in rats ${ }^{44)}$ and in red blood cell membranes after 2 weeks in pigs ${ }^{45)}$ after switching to experimental diets. Berlin et al. ${ }^{45)}$ also found that $(n-6)$ fatty acids increased the membrane fluidity more than (n-3) fatty acids.

PUFA are the principal chemical species vulnerable to free radical-initiated lipid peroxidation damage. Increasing PUFA intake may raise the cell membrane PUFA content and peroxidizability and changing PUFA intake resulted in a significant change in microsomal lipid peroxidation. Using an in vitro hepatocyte culture model, Lamb et $a l .{ }^{46)}$ showed that ethanol-dependent decreases in cell function were potentiated by 18:2 n- 6 and reduced by SFA (16:0). They proposed that PUFA but not SFA of membrane phospholipids were critical targets of active oxygen species such as hydroxyl radicals and superoxide anions. Therefore, increased PUFA intake may partially contribute to the increased tissue TBARS concentrations in rats fed a soybean oil diet.

GSH depletion can markedly compromise the overall antioxidant system because glutathione metabolism appears to be a crucial component of the overall defense against oxidative stress within a cell. ${ }^{25,37,47)}$ Our results showed that hepatic GSH, which was measured after intoxication with acetaminophen, was significantly lower in soybean oil fed animals than counterpart of those groups (Fig. 1). In fact, liver levels of GSH were decreased in the same animal groups which showed increased lipid peroxidation measured by TBARS $(r=-0.7093, p=0.0007)$. There are mounting evidences that GSH levels have inverse relationship with toxicity markers such as GPT/GOT/TBARS/MDA as well as lactate dehydrogenase (LDH) ${ }^{48-53)}$ For examples, ElMissiry et al. ${ }^{48)}$ reported the reverse relationship between GSH and GPT/GOT/TBARS/LDH in acute Adriamycin-induced cardiac and hepatic toxicity rat model and the other colleagues ${ }^{49,50)}$ reported the reverse relationship between GSH and GPT/GOT/LDH in acute carbon tetrachlorideinduced hepatotoxicity mice models.

However, McDanell et al. ${ }^{54)}$ reported that $10 \%$ butter diets were significantly higher toxic effects of acetaminophen than those from PUFA-rich margarine-fed rats by measuring leakage of LDH. Although it is controversial yet, mounting opposite evidences have been recently accumulated. For examples, Diniz et al. ${ }^{23)}$ reported that there was no difference of LDH leakage in SFA- and PUFA-fed rats for 5 weeks, showing that PUFA diet resulted in the highest levels of myocardial lipoperoxide and lipid hydroperoxide and decreased superoxide dismutase and catalase activities. Using pulmonary artery endothelial cells in vitro, treatment with $0.1 \mathrm{mmol} / \mathrm{l}$ 18:1 (beef tallow has more 18:1 than soybean oil) attenuated $\mathrm{H}_{2} \mathrm{O}_{2}$-mediated LDH release but the same dose of $18: 2$ and $18: 3$ potentiated cytotoxicity. ${ }^{55)}$ In addition, Nanji and his colleagues ${ }^{8-10,29,50)}$ have accumulated considerable evidences that SFA protect against alcohol-induced liver disease, whereas PUFA augment alcohol-induced hepatic fibrosis and necrosis in humans and animals. Collectively, PUFA has dual roles; beneficial effect on cardiovascular disease and deleterious effect on oxidative stress. Therefore, despite the study of McDanell et al. ${ }^{54)}$ it is not hard to conclude that SFArich diets prevent acetaminophen-induced hepatotoxicity compared to PUFA-rich diets with only GPT/GOT/TBARS/GSH data.

Another possible explanation for hepatoprotective effect of beef tallow is due to changes in TG levels. A decrease in hepatic phospholipid 20:4 n-6 would allow enhanced TG synthesis, because 20:4 $\mathrm{n}-6$ reduces hepatic TG synthesis. ${ }^{56}$ The decrease in 20:4 n-6 in beef tallow fed groups may be one possible mechanism for hepatoprotective effect in these groups. Nanji et al. ${ }^{57)}$ supported this evidence by showing that $20: 4 \mathrm{n}-6$ could not be synthesized 
to act as a target for free radical attack because beef tallow had very low 18:2 n-6.

In conclusion, data from the present study confirm that high PUFA diet can lead to increased in vivo susceptibility to hepatotoxicity, compared to rich SFA diet, irrespective of the amount of dietary fats. Furthermore, our data suggested that this high SFA diet had marked protection against the hepatotoxicity of acetaminophen by changing the fatty acid composition of membrane phospholipids, which aggravated the enhanced liver injury resulting from feeding diets high in PUFA. Many types of injury to cells involve production of free radicals or reactive oxygen species mostly caused by PUFA, which are now regarded as more healthful for the cardiovascular system and Reference Daily Intake. A clear demonstration that the fatty acids present in beef fat help reduce this kind of injury could lead to better understanding of what constitutes a healthy diet. Other types of dietary fats such as olive oils and/or chronic drug-induced hepatotoxicity need to be investigated for future study.

Acknowledgements This work was supported by 2009 Research Fund of College of Natural Sciences, Myongji University.

\section{REFERENCES}

1) Ervin, R. B., Wright, J. D., Wang, C. Y. and Kennedy-Stephenson, J. (2004) Dietary intake of fats and fatty acids for the United States population: 1999-2000. Adv. Data, 348, 1-6.

2) Ronis, M. J., Korourian, S., Zipperman, M., Hakkak, R. and Badger, T. M. (2004) Dietary saturated fat reduces alcoholic hepatotoxicity in rats by altering fatty acid metabolism and membrane composition. J. Nutr., 134, 904-912.

3) Cha, M. C. and Jones, P. J. (2000) Energy restriction dilutes the changes related to dietary fat type in membrane phospholipid fatty acid composition in rats. Metabolism, 49, 977-983.

4) Baumgardner, J. N., Shankar, K., Hennings, L., Badger, T. M. and Ronis, M. J. (2008) A new model for nonalcoholic steatohepatitis in the rat utilizing total enteral nutrition to overfeed a highpolyunsaturated fat diet. Am. J. Physiol. Gastrointest. Liver Physiol., 294, G27-G38.

5) Husveth, F., Manilla, H. A., Gaal, T., Vajdovich, P., Balogh, N., Wagner, L., Loth, I. and Nemeth, K. (2000) Effects of saturated and unsaturated fats with vitamin E supplementation on the antioxidant status of broiler chicken tissues. Acta Vet. Hung., 48, 6979.

6) Slim, R. M., Toborek, M., Watkins, B. A., Boissonneault, G. A. and Hennig, B. (1996) Susceptibility to hepatic oxidative stress in rabbits fed different animal and plant fats. J. Am. Coll. Nutr., 15, 289-294.

7) French, S. W., Morimoto, M., Reitz, R. C., Koop, D., Klopfenstein, B., Estes, K., Clot, P., IngelmanSundberg, M. and Albano, E. (1997) Lipid peroxidation, CYP2E1 and arachidonic acid metabolism in alcoholic liver disease in rats. J. Nutr., 127, 907S911S.

8) Nanji, A. A. (2004) Role of different dietary fatty acids in the pathogenesis of experimental alcoholic liver disease. Alcohol, 34, 21-25.

9) Nanji, A. A. and French, S. W. (2003) Animal models of alcoholic liver disease-focus on the intragastric feeding model. Alcohol Res. Health, 27, 325330.

10) Nanji, A. A., Khwaja, S. and Sadrzadeh, S. M. (1994) Decreased prostacyclin production by liver non-parenchymal cells precedes liver injury in experimental alcoholic liver disease. Life Sci., 54, 455-461.

11) Lands, W. E., Morris, A. and Libelt, B. (1990) Quantitative effects of dietary polyunsaturated fats on the composition of fatty acids in rat tissues. Lipids, 25, 505-516.

12) Lands, W. E., Libelt, B., Morris, A., Kramer, N. C., Prewitt, T. E., Bowen, P., Schmeisser, D., Davidson, M. H. and Burns, J. H. (1992) Maintenance of lower proportions of $(n-6)$ eicosanoid precursors in phospholipids of human plasma in response to added dietary (n - 3) fatty acids. Biochim. Biophys. Acta, 1180, 147-162.

13) Reeves, P. G., Nielsen, F. H. and Fahey, G. C., Jr. (1993) AIN-93 purified diets for laboratory rodents: final report of the American Institute of Nutrition ad hoc writing committee on the reformulation of the AIN-76A rodent diet. J. Nutr., 123, 1939-1951.

14) Porubsky, P. R., Meneely, K. M. and Scott, E. E. (2008) Structures of human cytochrome P-450 2E1. Insights into the binding of inhibitors and both small molecular weight and fatty acid substrates. J. Biol. Chem., 283, 33698-33707.

15) Kim, H. K., Choi, S. and Choi, H. (2004) Suppression of hepatic fatty acid synthase by feeding alphalinolenic acid rich perilla oil lowers plasma triacylglycerol level in rats. J. Nutr. Biochem., 15, 485492.

16) Gonzalez, F. J. (2005) Role of cytochromes P-450 in 
chemical toxicity and oxidative stress: studies with CYP2E1. Mutat. Res., 569, 101-110.

17) Speck, R. F. and Lauterburg, B. H. (1991) Fish oil protects mice against acetaminophen hepatotoxicity in vivo. Hepatology, 13, 557-561.

18) Jaya, D. S., Augstine, J. and Menon, V. P. (1993) Role of lipid peroxides, glutathione and antiperoxidative enzymes in alcohol and drug toxicity. Indian J. Exp. Biol., 31, 453-459.

19) Lim, S. P., Andrews, F. J. and O'Brien, P. E. (1994) Misoprostol protection against acetaminopheninduced hepatotoxicity in the rat. Dig. Dis. Sci., 39, 1249-1256.

20) Sedlak, J. and Lindsay, R. H. (1968) Estimation of total, protein-bound, and nonprotein sulfhydryl groups in tissue with Ellman's reagent. Anal. Biochem., 25, 192-205.

21) Ciuffi, M., Gentilini, G., Franchi-Micheli, S. and Zilletti, L. (1992) D-penicillamine affects lipid peroxidation and iron content in the rat brain cortex. Neurochem. Res., 17, 1241-1246.

22) Folch, J., Lees, M. and Sloane-Stanley, G. H. (1957) A simple method for the isolation and purification of total lipides from animal tissues. J. Biol. Chem., 226, 497-509.

23) Diniz, Y. S., Cicogna, A. C., Padovani, C. R., Santana, L. S., Faine, L. A. and Novelli, E. L. (2004) Diets rich in saturated and polyunsaturated fatty acids: metabolic shifting and cardiac health. Nutrition, 20, 230-234.

24) Kang, M. J., Shin, M. S., Park, J. N. and Lee, S. S. (2005) The effects of polyunsaturated:saturated fatty acids ratios and peroxidisability index values of dietary fats on serum lipid profiles and hepatic enzyme activities in rats. Br. J. Nutr., 94, 526-532.

25) Matthan, N. R., Dillard, A., Lecker, J. L., Ip, B. and Lichtenstein, A. H. (2009) Effects of dietary palmitoleic acid on plasma lipoprotein profile and aortic cholesterol accumulation are similar to those of other unsaturated fatty acids in the F1B golden Syrian hamster. J. Nutr., 139, 215-221.

26) Heyden, S. (1994) Polyunsaturated and monounsaturated fatty acids in the diet to prevent coronary heart disease via cholesterol reduction. Ann. Nutr. Metab., 38, 117-122.

27) Gaiva, M. H., Couto, R. C., Oyama, L. M., Couto, G. E., Silveira, V. L., Ribeiro, E. B. and Nascimento, C. M. (2003) Diets rich in polyunsaturated fatty acids: effect on hepatic metabolism in rats. Nutrition, 19, 144-149.

28) Kang, K. J. and Choi, S. S. (2008) Effects of conjugated linoleic acid supplementation on fatty acid composition in the plasma, liver, and epididymal fat pads of male-Sprague Dawley rats. J. Med. Food, 11, 435-442.

29) Nanji, A. A., Sadrzadeh, S. M. and Dannenberg, A. J. (1994) Liver microsomal fatty acid composition in ethanol-fed rats: effect of different dietary fats and relationship to liver injury. Alcohol Clin. Exp. Res., 18, 1024-1028.

30) Kuralay, F., Akarca, U. S., Ozutemiz, A. O., Kutay, F. and Batur, Y. (1998) Possible role of glutathione in prevention of acetaminophen-induced hepatotoxicity enhanced by fish oil in male Wistar rats. J. Toxicol. Environ. Health A, 53, 223-229.

31) Moussa, M., Tkaczuk, J., Ragab, J., Garcia, J., Abbal, M., Ohayon, E., Ghisolfi, J. and Thouvenot, J. P. (2000) Relationship between the fatty acid composition of rat lymphocytes and immune functions. Br. J. Nutr., 83, 327-333.

32) Buller, K. L. and Enser, M. (1986) The effects of food intake and dietary fatty acids on the activity of stearoyl-CoA $\Delta 9$-desaturase in pig adipose tissue. J. Agric. Sci., 106, 601-609.

33) Saito, M., Oh-Hashi, A., Kubota, M., Nishide, E. and Yamaguchi, M. (1990) Mixed function oxidases in response to different types of dietary lipids in rats. Br. J. Nutr., 63, 249-257.

34) Hennig, B., Enoch, C. and Chow, C. K. (1986) Linoleic acid hydroperoxide increases the transfer of albumin across cultured endothelial monolayers. Arch. Biochem. Biophys., 248, 353-357.

35) Tamura, H. and Shibamoto, T. (1991) Gas chromatographic analysis of malonaldehyde and 4-hydroxy2-(E)-nonenal produced from arachidonic acid and linoleic acid in a lipid peroxidation model system. Lipids, 26, 170-173.

36) Lee, C., Barnett, J. and Reaven, P. D. (1998) Liposomes enriched in oleic acid are less susceptible to oxidation and have less proinflammatory activity when exposed to oxidizing conditions. J. Lipid Res., 39, 1239-1247.

37) Camuesco, D., Galvez, J., Nieto, A., Comalada, M., Rodriguez-Cabezas, M. E., Concha, A., Xaus, J. and Zarzuelo, A. (2005) Dietary olive oil supplemented with fish oil, rich in EPA and DHA (n-3) polyunsaturated fatty acids, attenuates colonic inflammation in rats with DSS-induced colitis. J. Nutr., 135, 687694.

38) Hurtado de Catalfo, G. E., de Alaniz, M. J. and Marra, C. A. (2009) Influence of commercial dietary oils on lipid composition and testosterone production in interstitial cells isolated from rat testis. Lipids, 44, 345-357.

39) Teres, S., Barcelo-Coblijn, G., Benet, M., Alvarez, R., Bressani, R., Halver, J. E. and Escriba, P. V. 
(2008) Oleic acid content is responsible for the reduction in blood pressure induced by olive oil. Proc. Natl. Acad. Sci. U.S.A., 105, 13811-13816.

40) Nanji, A. A., Miao, L., Thomas, P., Rahemtulla, A., Khwaja, S., Zhao, S., Peters, D., Tahan, S. R. and Dannenberg, A. J. (1997) Enhanced cyclooxygenase-2 gene expression in alcoholic liver disease in the rat. Gastroenterology, 112, 943-951.

41) Ito, Y., Abril, E. R., Bethea, N. W., McCuskey, M. K. and McCuskey, R. S. (2006) Dietary steatotic liver attenuates acetaminophen hepatotoxicity in mice. Microcirculation, 13, 19-27.

42) Nanji, A. A., Sadrzadeh, S. M., Yang, E. K., Fogt, F., Meydani, M. and Dannenberg, A. J. (1995) Dietary saturated fatty acids: a novel treatment for alcoholic liver disease. Gastroenterology, 109, 547-554.

43) Yoo, J. S., Hong, J. Y., Ning, S. M. and Yang, C. S. (1990) Roles of dietary corn oil in the regulation of cytochromes P-450 and glutathione S-transferases in rat liver. J. Nutr., 120, 1718-1726.

44) Hammer, C. T. and Wills, E. D. (1979) The effect of dietary fats on the composition of the liver endoplasmic reticulum and oxidative drug metabolsim. $\mathrm{Br} . \mathrm{J}$. Nutr., 41,465-475.

45) Berlin, E., Bhathena, S. J., McClure, D. and Peters, R. C. (1998) Dietary menhaden and corn oils and the red blood cell membrane lipid composition and fluidity in hyper- and normocholesterolemic miniature swine. J. Nutr., 128, 1421-1428.

46) Lamb, R. G., Koch, J. C., Snyder, J. W., Huband, S. M. and Bush, S. R. (1994) An in vitro model of ethanol-dependent liver cell injury. Hepatology, 19, 174-182.

47) Nemeth, K., Mezes, M., Gaal, T., Bartos, A., Balogh, K. and Husveth, F. (2004) Effect of supplementation with methionine and different fat sources on the glutathione redox system of growing chickens. Acta Vet. Hung., 52, 369-378.

48) El-Missiry, M. A., Othman, A. I., Amer, M. A. and Bd el-Aziz, M. A. (2001) Attenuation of the acute adriamycin-induced cardiac and hepatic oxidative toxicity by $\mathrm{N}$-(2-mercaptopropionyl) glycine in rats.
Free Radic. Res., 35, 575-581.

49) Ma, S. F., Nishikawa, M., Katsumi, H., Yamashita, F. and Hashida, M. (2006) Liver targeting of catalase by cationization for prevention of acute liver failure in mice. J. Control. Release, 110, 273-282.

50) Liu, J., Tan, H., Sun, Y., Zhou, S., Cao, J. and Wang, F. (2009) The preventive effects of heparinsuperoxide dismutase on carbon tetrachlorideinduced acute liver failure and hepatic fibrosis in mice. Mol. Cell. Biochem., 327, 219-228.

51) Brenes, A., Centeno, C., Viveros, A. and Arija, I. (2008) Effect of enzyme addition on the nutritive value of high oleic acid sunflower seeds in chicken diets. Poult. Sci., 87, 2300-2310.

52) Wills, P. J. and Asha, V. V. (2006) Protective effect of Lygodium flexuosum (L.) Sw. extract against carbon tetrachloride-induced acute liver injury in rats. J. Ethnopharmacol., 108, 320-326.

53) Pereira, C., Mapuskar, K. and Rao, C. V. (2006) Chronic toxicity of diethyl phthalate in male Wistar rats-a dose-response study. Regul. Toxicol. Pharmacol., 45, 169-177.

54) McDanell, R. E., Beales, D., Henderson, L. and Sethi, J. K. (1992) Effect of dietary fat on the in vitro hepatotoxicity of paracetamol. Biochem. Pharmacol., 44, 1303-1306.

55) Karman, R. J., Gupta, M. P., Garcia, J. G. and Hart, C. M. (1997) Exogenous fatty acids modulate the functional and cytotoxic responses of cultured pulmonary artery endothelial cells to oxidant stress. $J$. Lab. Clin. Med., 129, 548-556.

56) Kim, H. J., Choi, E. S. and Wade, A. E. (1990) Effect of dietary fat on the induction of hepatic microsomal cytochrome P-450 isozymes by phenobarbital. Biochem. Pharmacol., 39, 1423-1430.

57) Nanji, A. A., Zhao, S., Lamb, R. G., Sadrzadeh, S. M., Dannenberg, A. J. and Waxman, D. J. (1993) Changes in microsomal phospholipases and arachidonic acid in experimental alcoholic liver injury: relationship to cytochrome P-450 2E1 induction and conjugated diene formation. Alcohol Clin. Exp. Res., 17, 598-603. 